\title{
COVID-19 in Sub-Saharan African Countries: Association between Compliance and Public Opinion
}

Chikasirimobi Goodhope Timothy ${ }^{1}$, Deborah Donald Charwe ${ }^{2}$, Uchechukwu L Osuagwu ${ }^{3}$, Chundung Asabe Miner $^{4}$, Emmanuel Kwasi $\mathrm{Abu}^{5}$, Godwin Ovenseri-Ogbomo ${ }^{6}$, Piwuna Christopher Goson ${ }^{7}$, Raymond Langsi ${ }^{8}$, Bernadine Ekpenyong ${ }^{9}$, Richard Oloruntoba ${ }^{10}$, Obinna Nwaeze ${ }^{11}$, Prof. Tanko Ishaya ${ }^{12}$, Prof. Khathutshelo Percy Mashige ${ }^{13}$ \& Kingsley Agho ${ }^{14}$

${ }^{1}$ Masinde Muliro University of Science and Technology, Kakamega Kenya

${ }^{2}$ Tanzania Food and Nutrition Centre, P.O.Box 977 Dar es Salaam, Tanzania

${ }^{3}$ Diabetes, Obesity and Metabolism Translational Research Unit, Western Sydney University, Campbelltown, NSW 2560, Australia

${ }^{4}$ Department of Community Medicine, College of Health Sciences, University of Jos, Nigeria

${ }^{5}$ Department of Optometry and Vision Science, School of Allied Health Sciences, College of Health and Allied Sciences, University of Cape Coast, Ghana

${ }^{6}$ Department of Optometry, College of Applied Medical Sciences, Qassim University, Saudi Arabia; Department of Optometry, Faculty of Life Sciences and University of Benin, Benin City, Nigeria; African Eye and Public Health Research Initiative, Nigeria

${ }^{7}$ Department of Psychiatry, College of Health Sciences, University of Jos, Nigeria

${ }^{8}$ Health Division, University of Bamenda ,Bambili ,Cameroon

${ }^{9}$ Department of Public Health, Faculty of Allied Medical Sciences, College of Medical Sciences, University of Calabar, Cross River State, Nigeria

${ }^{10}$ Curtin Business School, Curtin University, Bentley WA 6151, Australia

${ }^{11}$ NHS, United Kingdom

${ }^{12}$ Department of Computer Science, University of Jos, Nigeria

${ }^{13}$ African Vision Research Institute, Discipline of Optometry, University of KwaZulu-Natal, Westville Campus, Durban, 3629, South Africa

${ }^{14}$ School of Science and Health, Western Sydney University, Campbelltown, NSW 2560, Australia

Correspondence: Chikasirimobi Timothy, Masinde Muliro University of Science and Technology, Kakamega Kenya

Received: November 3, 2020 Accepted: December 6, 2020 Online Published: January 3, 2021

doi:10.5539/gjhs.v13n2p91 URL: https://doi.org/10.5539/gjhs.v13n2p91

\begin{abstract}
Background: The outbreak of coronavirus disease (COVID-19) has created a global public health crisis and non-compliance with public health measures to contain the infection poses a challenge to Sub-Saharan African governments. This study investigated the associations between compliance and public opinion on COVID-19 public health containment measures across selected SSA countries.

Method: Anonymous online cross-sectional survey was administered to 1779 adults (18 years and older) during the mandatory lockdown period in most African countries (April 18 - May 16, 2020). Respondents were recruited via Facebook, WhatsApp, and authors' networks. Data on participants' socio-demographics, their opinions regarding the precautionary measures against COVID-19, and their compliance with preventive measures were collected. Multiple logistic regression analysis was used to examine the association between compliance and public opinions about COVID-19.
\end{abstract}

Results: Respondents who did not think that public health authorities in their countries were doing enough to control the COVID-19 outbreak were more likely to attend crowded places (aOR 1.75, 95\% CI 1.30-2.35). Those 
who thought COVID-19 would not remain in their countries (aOR 0.48, 95\% CI $0.24-0.96$ ) and those who thought self-isolation is not needed during the pandemic (aOR $0.29,95 \%$ CI $0.13-0.65$ ) were less likely to encourage others to comply with the strategies put in place to prevent the spread of the disease. Participants who thought the COVID-19 outbreak was dangerous and those wearing medical masks were found to wash their hands with soap under running water.

Conclusion: The study showed that public opinion influenced the compliance of individuals to public health measures for containment and mitigation of COVID-19. There is a need to improve compliance by the public.

Keywords: COVID-19, compliance, public opinion, public health measures, Sub-Saharan Africa

\section{Introduction}

The year 2020 had been a troubling year occasioned by the outbreak of the novel coronavirus disease (COVID-19). In less than six months following its outbreak in Wuhan, China, the condition, declared a global pandemic by the World Health Organization (WHO)(WHO, 2020a; Xiao \& Torok, 2020), had ravaged the globe and caused fear, panic, economic disruption and deaths worldwide. COVID-19 had affected more than six million people worldwide as at the first week of June 2020, with a tremendous rising toll of deaths (Roser, Ritchie, Ortiz-Ospina, \& Hasell, 2020).

Nations at the early stages of the disease outbreak, took it as the normal flu, a common respiratory-related disease or just another self-limiting viral infection that would resolve with time. As at March 2020, when WHO declared COVID-19 a pandemic, many countries were still not certain of actions to be taken or strategies to be adopted to prevent the spread of the infection (Cucinotta \& Vanelli, 2020).

With the rapid global spread of the disease, the rising number of infections and mortality, different countries had to institute strategies to control the spread of the infection. Self-Isolation, quarantine, and lockdowns were some of the measures taken by governments across different countries (Xiao \& Torok, 2020). Furthermore, WHO provided guidelines including handwashing with soap under running tap, use of alcohol-based hand sanitizers, cough etiquette, wearing of the N95 mask (for medical professionals), observing the $1 \mathrm{~m}-1.5 \mathrm{~m}$ social distancing and avoiding social gatherings among others (Lewnard \& Lo, 2020; Liu, He, Rong, \& Tang, 2020), to mitigate the spread of the infection. Despite the implementation of these measures, there were reports of increasing rates of infection.

Countries in the Sub-Saharan African (SSA) regions were dealing with the COVID-19 by adopting and modifying the measures mentioned above to suit their political, economic, social and development levels (Ataguba, 2020; Ekpenyong et al., 2020). However, there were fears of increasing infections and so much uncertainty as to the future of this viral infection coupled with the fatalistic perception about the outcome of the disease (Zhao et al., 2020).

Compliance meant the acceptance and effective application of the measures that were put in place by governments to curb the spread of the COVID-19 disease (Ekpenyong et al., 2020; Ovenseri-Ogbomo et al., 2020; Plohl \& Musil, 2020). This study sought to examine the associations between compliance with the measures put in place and public opinions on COVID-19 in sub-Saharan Africa. If the government directives were to be well-coordinated, it is important that they be initiated more efficiently. Through the findings of this study, the factors associated with compliance were identified, and for which the understanding of the interplay of these factors is useful when planning future interventions in future pandemics.

\section{Methods}

\subsection{Ethics and Consent}

The study adhered to the principles of the Helsinki declaration (WMA, 2001), and the protocol was approved by the Human Research Ethics Committee of the University of Calabar. Participation was anonymous and voluntary. Informed consent was obtained from all participants prior to commencement of the study and after the study protocol has been explained. Participants consented to voluntarily participate in this study by answering either a 'yes' or 'no' to the question inquiring whether they voluntarily agree to participate in the survey. A 'no' response meant that the participants could not progress in answering the survey questions and were excluded from the study.

\subsection{Study Design}

This cross-sectional descriptive study was carried out during the mandatory lockdown period (27 April - 17 May 2020) for most African countries. Data was obtained electronically via survey monkey with a survey link posted on the commonly used and easily accessible social media platforms - WhatsApp and Facebook - to elicit a better response. In addition, survey links were shared through the authors' emails and direct short message services. 
To be eligible for participation, respondents had to be Sub-Saharan Africans aged 18 years or older; and be able to provide online consent by answering a 'yes' or 'no' response before starting the survey to indicate their willingness to participate in this study. Survey distribution covered SSA countries such as Ghana, Cameroon (only distributed to the English-speaking regions), Nigeria, South Africa, Tanzania, Kenya and Uganda.

\subsection{Survey Questionnaire}

The questionnaire included a brief overview of the context, purpose, procedures, nature of participation, privacy and confidentiality statements and statements to be responded to. The survey tool was developed based on the guidelines from the WHO for clinical and community management of COVID-19 (WHO, 2020a, 2020b), and adapted with modifications to suit the objectives of this study. A pilot study was conducted to ensure clarity and understanding as well as to determine the duration for completing the questionnaire prior to distribution. This self-administered online questionnaire consisted of 17 items of two sections (demographic characteristics and practice/compliance). The demographic variables included questions on age, gender, marital status, education, employment and religion. The questions included closed-ended questions with "Yes" (score 1) to "No" (score -1) and a five-point 'Likert-type scale' to score participants' responses. A 'Not Sure' response was scored as 'zero'. For responses utilizing Likert scale, the scores ranged from '0" for 'Always/A great deal'; "1" for 'Sometimes/A lot'; "2" for 'Rarely/A moderate amount'; "3" for 'Not at all/A little' and "4" for 'Not Sure/ Not at all'.

Respondents were asked about their compliance towards the public health measures put in place by the various SSA countries to mitigate and contain the spread of COVID-19. The compliance score ranged from 5-20 points and was divided into 3 categories. The bottom $<5.0 \%$ of scores was arbitrarily referred to as 'poor compliance', the next $12.5 \%$ as 'moderate compliance', and the top $\geq 20.0 \%$ as 'good compliance'.

\subsection{Dependent Variables}

The outcome variable was compliance to the eight government policies designed to contain and mitigate the spread of COVID-19: attendance at crowded places, handwashing with soap under running water, self-isolation, quarantine, use of facemask when going out, no outside travels, purchase of hand sanitizers and encouraging others to comply with government guidelines, which are shown in Supplementary Table S1.

\subsection{Exposure Variables}

The exposure variables for this study were the public opinion, which included six variables that were associated with the government policies to prevent the spread of the disease. The public opinion variables used in the analysis were; if the respondents thought the COVID-19 outbreak was dangerous, If they thought public health authorities in their countries were doing enough to control the C0VID-19 outbreak, If they thought hand hygiene or hand-cleaning was important in the control of the spread of COVID-19; and if they considered the self-isolation as necessary and reasonable.

\subsection{Independent Variables}

The independent variable was the demographic factors, which included age group, gender, SSA region, country of residence, employment status, marital status, religion, level of education, occupation and whether they lived alone or not.

\subsection{Statistical Analysis}

Data analysis was performed using Stata version 14.1 (Stata Corp. College Station United States of America). Categorical variables were presented as frequencies and percentages. This was followed by the estimation of the proportion of each compliance response or public opinion response, and the differences between proportions were evaluated using $95 \%$ confidence intervals (CI). The outcome variable was compliance, which was categorized into 'poor, moderate and good compliance'. All the independent variables shown in Table 1 were then entered into a multivariate model to estimate the associated factors by adjusted ORs and $95 \%$ CIs.

\section{Results}

\subsection{Characteristics of the Population}

Table 1 shows the characteristics of all study participants and summary of responses used in the predictive modelling of compliance and public opinion. A total of 1779 (male to female ratio of 1.3:1) completed the survey. From the table, most of the respondents had at least a university degree $n=1563(87.6 \%)$, were younger than 38 years $n=1158(65.3 \%)$ and employed $n=1189(66.7 \%)$. Nearly all participants $n=1644(92.5 \%)$ were residing in their respective countries of origin at the time of this study. 
Table 1. Demographic characteristics of the respondents in this study $(n=1779)$

\begin{tabular}{|c|c|c|}
\hline Characteristics & Frequency & Percent \\
\hline \multicolumn{3}{|l|}{ Region } \\
\hline West Africa & 982 & 56.21 \\
\hline East Africa & 181 & 10.36 \\
\hline Central Africa & 221 & 12.65 \\
\hline South Africa & 363 & 20.78 \\
\hline \multicolumn{3}{|l|}{ Country of residence } \\
\hline Africa & 1,644 & 92.52 \\
\hline Outside of Africa & 133 & 7.48 \\
\hline \multicolumn{3}{|l|}{ Age classification } \\
\hline 18-28 years & 676 & 38.13 \\
\hline 29-38 & 482 & 27.19 \\
\hline $39-48$ & 390 & 22.00 \\
\hline $49+$ years & 225 & 12.68 \\
\hline \multicolumn{3}{|l|}{ Sex } \\
\hline Males & 993 & 55.98 \\
\hline Females & 781 & 44.02 \\
\hline \multicolumn{3}{|l|}{ Working status } \\
\hline Employed & 1189 & 66.72 \\
\hline Unemployed & 593 & 33.28 \\
\hline \multicolumn{3}{|l|}{ Marital status } \\
\hline Married & 790 & 44.43 \\
\hline not married & 988 & 55.57 \\
\hline \multicolumn{3}{|l|}{ Religion } \\
\hline Christian & 1571 & 88.31 \\
\hline Others $\uparrow$ & 208 & 11.69 \\
\hline \multicolumn{3}{|l|}{ Level of Education } \\
\hline Master's Degree or more & 592 & 33.22 \\
\hline Bachelor's Degree & 971 & 54.49 \\
\hline Secondary/primary & 219 & 12.29 \\
\hline \multicolumn{3}{|l|}{ Occupation } \\
\hline Non healthcare & 1,300 & 77.0 \\
\hline Healthcare & 388 & 23.0 \\
\hline \multicolumn{3}{|l|}{ Household factors } \\
\hline \multicolumn{3}{|l|}{ Lived alone during COVID } \\
\hline No & 327 & 18.4 \\
\hline Yes & 1,454 & 81.6 \\
\hline \multicolumn{3}{|l|}{ How many live together } \\
\hline$<3$ people & 452 & 29.0 \\
\hline 4-6 people & 802 & 51.5 \\
\hline 6 or more people & 303 & 19.5 \\
\hline
\end{tabular}


Figure 1 presents the outcome variables of compliance with public health measures put in place to control the spread of the virus in SSA. From this figure, there was good compliance with encouraging others to comply with government policies and washing hands with soap under running water, average/moderate compliance with the use of facemasks and poor compliance with self-isolation, quarantine as well as avoiding large gatherings, whereas one in every seven respondent attended a crowded place during the lockdown.

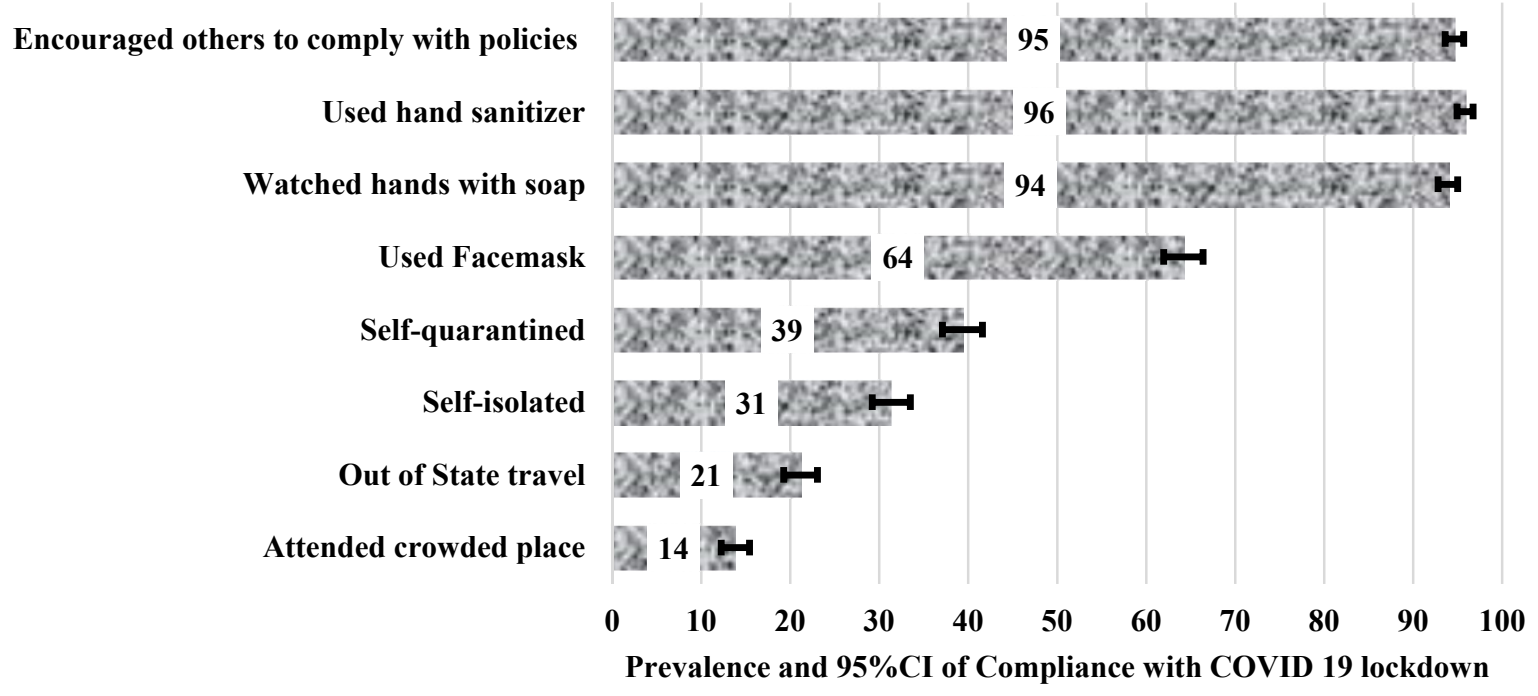

Figure 1. Compliance with COVID-19 public health measures

Result presented prevalence a 95\% confidence interval (CI)

\subsection{Multivariable Analysis}

Figure 2 presents the adjusted odds ratio and confidence interval for the association between public opinion and compliance with government policies to stop the spread of COVID-19. After adjusting for all demographic variables, respondents who reported that the public health authorities in their countries were not doing enough to minimize the spread of the disease were more likely to go to crowded places during the pandemic (aOR 1.75, 95\% CI 1.30-2.35). Supplementary Table S2 shows the factors associated with the public health measures put in place to contain and mitigate the diseases. The practice of self-isolation and quarantine were associated with the thought that COVID-19 would be gone after the lockdown, whereas washing hands with soap were associated with the opinion that COVID-19 was dangerous and could be prevented by wearing of the facemask.

Respondents who thought that COVID-19 would not remain in their countries (aOR 0.48, 95\% CI $0.24-0.96$ ) and those who thought self-isolation was not needed during the pandemic (aOR $0.29,95 \%$ CI $0.13-0.65$ ) were less likely to encourage others to comply with the preventive strategies put in place to stop the spread of the disease.

\subsection{Associated Factors with Compliance with Government Policies}

In addition to the factors identified in Figure 2, other factors that were associated with compliance to government policies to stopping the spread of the disease in SSA were old age, being resident in East and Central Africa, living alone during the lockdown, female sex, being employed, and marital status (unmarried). See Supplementary Table 2 for details. 


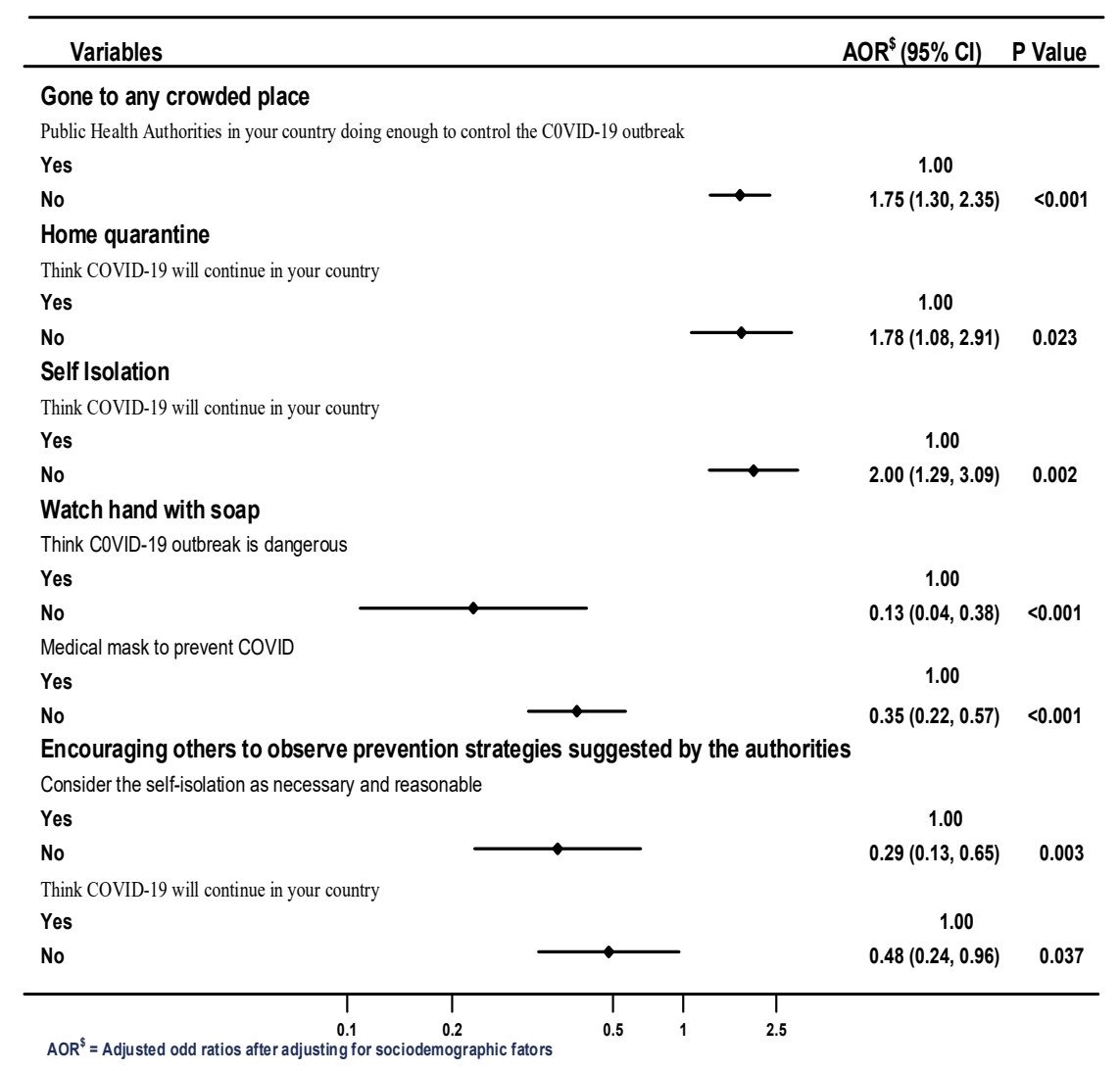

Figure 2. Association between public opinion and compliance with government policies. Showing variables with significance in the multivariable analysis

Result presented as adjusted Odds ratio at $95 \%$ confidence interval and $p$ value at significance $p=0.05$

\section{Discussion}

In this study, we investigated the association between compliance and public opinion toward measures taken during the COVID-19 in Sub-Saharan African countries. The results indicated that there was generally good compliance with the measures recommended for the mitigation of the spread of COVID-19 amongst the respondents with hand hygiene recording the highest compliance level while out-of-state travel and avoidance of crowded gathering complied with the least. However, the level of compliance varied from one SSA region to another. The results further showed that opinion on how respective governments were handling the pandemic and whether the pandemic would be curtailed influenced respondents' compliance to prescribed measures to address the spread of infection and hence deal with the pandemic.

The opinion that the public health authorities in the respective SSA countries were not doing enough to minimize the spread of the diseases was associated with attending public gatherings during the pandemic and poor compliance to social distancing. In an opinion poll, (Ipsos, 2020) it was asserted that the public was divided on whether self-isolation, travel restrictions and social distancing could contain the spread of the coronavirus disease and thus were reluctant to comply with these measures. A broadcast by Gallup Pakistan reported that the public had the belief that government was not actually doing enough through the public health authorities which is in agreement with the findings of this study (Pakistan, 2020). An Israeli study argued that the citizens' refusal to comply with public health measures to control the spread of COVID-19 is expectedly a characteristic of human behaviour and concluded that the escalation of the disease was thought to come from individual behaviour and may not be related to activities of public health authorities (Mansdorf, 2020). From the psychological front, humans are predisposed to refusal and denial. In this case, they are referred to as refusers, since they are in denial, and this opposes the containment measures (Mansdorf, 2020). Public health activity slacking in implementation is also a threat to the people, and there is a need to ensure that public health activities are made to reach the populace. This could be achieved effectively by concerted efforts at educating the populace on the containment and mitigation 
measures in place as set out by the governments of these countries.

Respondents who thought that COVID-19 would remain in their countries after the lockdown were less likely to comply with the mitigation practices, including self-isolation and self-quarantine. Starting as a conspiracy theory, most people believe that COVID-19 has come to stay (Ahmed, Vidal-Alaball, Downing, \& Seguí, 2020; Aiyewumi \& Okeke, 2020; Bierwiaczonek, Kunst, \& Pich, 2020; Bruder \& Kunert, 2020; Coë; Durkee, 2020; Ovenseri-Ogbomo et al., 2020). Cultural practices in most SSA countries tend to influence beliefs that the COVID-19 issue is a phase that will disappear as it appeared (Aiyewumi \& Okeke, 2020; Ovenseri-Ogbomo et al., 2020). Reports from the US death toll conspiracy theory set divided views on the duration and death toll of the COVID-19 (Durkee, 2020). The child welfare department in the US has accepted the permanency of the COVID-19 and thus are concerned on how to live through and with evolving variants and socio-economic fluctuations associated with COVID-19 (Tierney, Stevens, \& Armbrust, 2020). This report is in line with the findings of this study with the spark of interest in finding solutions on the trending of the Coronavirus disease.

An important dimension to the compliance challenges according to the belief of the permanency of the pandemic is the religious propagation of the disease as an act of divinity to check the activities of men. It is stated that about $63 \%$ of Christians in American believe the pandemic is a message from God with Evangelical Protestants the most likely to believe that strong compared to mainline Protestants and Catholics (Schor \& Fingerhut, 2020). This is in agreement with the finding of significant associations between religion and compliance with the government directives were respondents in this study (Schor \& Fingerhut, 2020). We found that Christians were more likely to attend crowded events and embark on out of state travel during the lockdown period compared to those who were Muslims. SSA countries demonstrate an affinity for the religion and so much expression of this is seen on the way countries in these regions had strong oppositions from religious leaders at the beginning of the pandemic and even having these leaders promote some conspiracy theories on COVID-19 pandemic including the 5g myth and that vaccination for COVID-19 is the mark of the beast (Files, 2020).

The workplace policies of working from home, as set out by many countries during the pandemic tend to give credence to the belief that COVID-19 is here to stay (Tang et al., 2020). The passing into law stringent measures that are perceived could become permanent in some countries (Cormacain, 2020; Van Natta et al., 2020) agrees with the findings of this study. In trying to map a road ahead for Indians in small villages, rural and urban settlements, the challenges encountered as a result of the global pandemic remains a thing of uncertainty regarding its permanency as shown in studies in this Indian settlement (Ananth, 2020). This calls for thorough governmental and individual investigations to ascertain the actual dimensions of the COVID-19 and its evolving trends with respect to educating all appropriately on adoption and compliance to the containment and mitigation measures in order to save and preserve lives following the rising numbers in global infections and deaths.

Another interesting finding of this study was the fact that respondents who disagreed that COVID-19 was dangerous and those who thought that the use of medical facemask was not preventative during COVID-19 were less likely to comply with the public health practices. Furthermore, many respondents reported compliance with wearing facemask when going out to the public, and this was associated with being resident in East and Central Africa. Also, people aged older than 29 years, being female, being unemployed and not married were associated with compliance to differing degrees in SSA. The findings are consistent with a study conducted in Malaysia whereby more than half of the participants reported wearing a face mask when going out in public $(51.2 \%)$ and this was significantly associated with gender, age group, region, occupation, and income group (Azlan, Hamzah, Sern, Ayub, \& Mohamad, 2020). Azlan et al. (2020), reported similar findings of good compliance in the practice of proper hand hygiene at the time the study was conducted in late March and found that this was associated with gender, age group, region, and occupation.

In this study, encouraging others to observe the public health measures put in place during the pandemic was associated with the perception of the disease duration and as such the lack of need to self-isolate during the pandemic. In the present study, almost a quarter of the respondents embarked on out of state travel despite recommendation not to do so. This low compliance may be due to the belief that social distancing measures such as travel bans, and self-isolation would not prevent the spread of the virus (Seale et al., 2020). This study went further to assess compliance in practicing self-isolation and quarantine. Those living in Central Africa, aged older than 39 years, being Muslims and living with others were significantly associated with being quarantined except for those who were unemployed and lived in East Africa. On the other hand, those older than 29 years old that were unmarried and held a bachelor's degree were significantly associated with self-isolation. There was no change in being quarantined and practicing self-isolation in East Africa, but the practice reduced in Central Africa.

Similar to this study, Bodas and Peleg (2020) stated that being assured of household incomes during times of 
quarantine and self-isolation are important determinants of compliance. However, noncompliance was more observed in males, those who were married and less educated. In a study (Seale et al., 2020), the most common avoidance behavior adopted was keeping away from crowded places generally (67\%). The opinion and compliance of the respondents among SSA countries play a vital role in enhancing the effective implementation of the measures provided by WHO to eliminate the spread of COVID-19 disease (WHO, 2020a). Those who believed that the COVID 19 disease was dangerous were more complying to government policies. Furthermore, the process of encouraging other people to comply with government directives was more practiced by those who believed that there was a need for self-isolation. As we continue fighting the spread of this pandemic, programs should focus on younger ones, unemployed and those who are living in West and Southern Africa. In addition, sex and marital status should be vital components that can help reduce effects on compliance, seeing that male respondents are more non-compliant and married people more compliant. This area needs to explore it further to ascertain the actual rate of influence of these factors.

This study had some limitations. Given the inability to physically access respondents due to the pandemic, the survey tool was sent out to prospective respondents electronically using social media platforms and emails. This method of soliciting respondents may have inadvertently excluded respondents who may not have access to the internet from participating in the study. Thus, it may not be a true reflection of the opinion of those living in rural areas where internet penetration remains relatively low (Hjort \& Poulsen, 2019). However, the use of an internet-based methodology for this study, allowed for the rapid acquisition of responses from wide geographical distribution and this was the only reliable means to disseminate information at the time of this study. Furthermore, the survey was presented in the English language, thus excluding non-English speakers from the study area from participating. It was also noted that the sample of this study is biased towards West Africans, literates, and English speaking SSAs. These unintended biases should be noted when interpreting and applying the results because the findings cannot be generalized in all SSA countries. The low participation of respondents from other sub-regions like East Africa may have been occasioned by the lockdown as citizens from Tanzania were asked to refrain from giving out information regarding the pandemic. Notwithstanding these limitations, this study is the first SSA regional study that provides evidence on the impact of public opinion about the pandemic on compliance status on mitigation practices. The confounders were held constant at each step of the analysis in order to reduce the issue of bias. In addition, the study provides useful information for reducing the additional burden associated with non-compliance to these practices.

\section{Conclusion}

From the study, it is seen that there was good compliance with the public health measures set out by the different governments to contain and mitigate the spread of the coronavirus infection. The opinion held by respondents with respect to the handling of the pandemic by various governments in SSA and whether the pandemic will abate had a significant influence on the compliance with the public health measures. There was a vast regional variation in compliance and opinion held by respondents with respect to the public health measures put in place to control the COVID-19 pandemic.

\section{What is already known on this topic?}

- The multiple dimensional approaches to formulating measures aimed at mitigating the COVID-19 spread and infection created more fear among the public.

- Rapid response committees were set up in sub-Saharan African countries who responded to calls on the control of the infection and spread of the coronavirus.

- There were demonstrated skepticisms in the uptake of the measures set out by countries in SSA, particularly among the rural dwellers and confusion on which measures will serve best to stop the disease entirely among the urban dwellers.

\section{What this study adds}

- The findings of this study showed good compliance with measures recommended for the mitigation of the spread of COVID-19 amongst the respondents with high compliance with hand hygiene and low compliance with out-of-state travel and avoidance of crowded gathering.

- Compliance to the mitigation practices was mostly driven by people's opinion on how respective governments were handling the pandemic and whether the pandemic will be curtailed.

- The unfulfilling role of public health protocols in the SSA countries and the need to institute implementation measures to the stipulated control measures was highlighted. 


\section{Authors' Contributions}

All authors made substantial contributions to the conception or design of the work; or the acquisition, analysis, or interpretation of data for the work; TC, DC, LO and KA drafted the work; KA, MC, RO, RL, ON, CP, EA, GO, CT, DC, TI, KM, BE, revised it critically for important intellectual content; all authors approved the final version to be published; and TC, DC, LO, and KA agree to be accountable for all aspects of the work in ensuring that questions related to the accuracy or integrity of any part of the work are appropriately investigated and resolved.

\section{Funding}

This research did not receive any funding

\section{Acknowledgements}

Thanks to all authors for their concerted and rigorous review and inputs to the final manuscript

\section{Competing Interests Statement}

The authors have no financial disclosures to make and no conflict of interest.

\section{References}

Ahmed, W., Vidal-Alaball, J., Downing, J., \& Seguí, F. L. (2020). COVID-19 and the 5G conspiracy theory: social network analysis of Twitter data. Journal of Medical Internet Research, 22(5), e19458. https://doi.org/10.2196/19458

Aiyewumi, O., \& Okeke, M. I. (2020). The myth that Nigerians are immune to SARS-CoV-2 and that COVID-19 is a hoax are putting lives at risk. Journal of global health, 10(2). https://doi.org/10.7189/jogh.10.020375

Ananth, S. (2020, July 9, 2020). Covid-19 is changing economic activity in small town and rural India - Will these changes become permanent? Deccan Herald. Retrieved from https://www.deccanherald.com/opinion/covid-19-is-changing-economic-activity-in-small-town-and-rural-in dia-will-these-changes-become-permanent-858935.html

Ataguba, J. E. (2020). COVID-19 pandemic, a war to be won: understanding its economic implications for Africa. Springer. https://doi.org/10.1007/s40258-020-00580-x

Azlan, A. A., Hamzah, M. R., Sern, T. J., Ayub, S. H., \& Mohamad, E. (2020). Public knowledge, attitudes and practices towards COVID-19: A cross-sectional study in Malaysia. PloS one, 15(5), e0233668. https://doi.org/10.1371/journal.pone.0233668

Bierwiaczonek, K., Kunst, J. R., \& Pich, O. (2020). Belief in COVID-19 conspiracy theories reduces social distancing over time. Applied Psychology: Health and Well-Being. https://doi.org/10.31234/osf.io/tqfrw

Bodas, M., \& Peleg, K. (2020). Self-Isolation Compliance In The COVID-19 Era Influenced By Compensation: Findings From A Recent Survey In Israel: Public attitudes toward the COVID-19 outbreak and self-isolation: a cross sectional study of the adult population of Israel. Health Affairs, 39(6), 936-941. https://doi.org/10.1377/hlthaff.2020.00382

Bruder, M., \& Kunert, L. (2020). The conspiracy hoax? Testing key hypotheses about the correlates of generic beliefs in conspiracy theories during the COVID-19 pandemic.

Coë, C. (29 July 2020). Melbourne conspiracy theorist behind anti-masker "rule book" believes COVID-19 is a hoax. Daily Mail Australia. Retrieved https://www.dailymail.co.uk/news/article-8567661/Melbourne-conspiracy-theorist-anti-masker-rule-book-b elieves-COVID-19-hoax.html

Cormacain, R. (2020). Keeping Covid-19 emergency legislation socially distant from ordinary legislation: principles for the structure of emergency legislation. The Theory and Practice of Legislation, 1-21. https://doi.org/10.1080/20508840.2020.1786272

Cucinotta, D., \& Vanelli, M. (2020). WHO declares COVID-19 a pandemic. Acta Bio Medica: Atenei Parmensis, 91(1), 157.

Durkee, A. (2020). Nearly A Third Of Americans Believe Covid-19 Death Toll Conspiracy Theory. Forbes. Retrieved from https://www.forbes.com/sites/carltonreid/2020/11/28/legal-battle-looms-after-confirmation-that-700000-pop -up-cycleway-on-kensington-high-street-to-be-removed/?sh=1338b5753702

Ekpenyong, B., Obinwanne, C. J., Ovenseri-Ogbomo, G., Ahaiwe, K., Lewis, O. O., Echendu, D. C., \& Osuagwu, U. L. (2020). Assessment of Knowledge, Practice and Guidelines towards the Novel COVID-19 among Eye 
Care Practitioners in Nigeria-A Survey-Based Study. International journal of environmental research and public health, 17(14), 5141. https://doi.org/10.3390/ijerph17145141

Files, V. (2020, May 18). A conspiracy theory linking fifth-generation $(5 G)$ technology, radio-frequency Vera Files: $\begin{array}{llll}\text { Truth } & \text { our } & \text { business. } & \text { Retrieved }\end{array}$ $\mathrm{https}$ ///verafiles.org/articles/vera-files-fact-check-fb-posts-float-conspiracy-theory-5g-rf

Hjort, J., \& Poulsen, J. (2019). The arrival of fast internet and employment in Africa. American Economic Review, 109(3), 1032-1079. https://doi.org/10.1257/aer.20161385

Ipsos. (2020). Public divided on whether isolation, travel bans prevent COVID-19 spread; border closures become more acceptable [Press release]. https://www.ipsos.com/sites/default/files/ct/news/documents/2020-03/press-release.pdf

Lewnard, J. A., \& Lo, N. C. (2020). Scientific and ethical basis for social-distancing interventions against COVID-19. The Lancet. Infectious Diseases, 20(6), 631. https://doi.org/10.1016/S1473-3099(20)30190-0

Liu, P., He, S., Rong, L., \& Tang, S. (2020). The effect of control measures on COVID-19 transmission in Italy: Comparison with Guangdong province in China. https://doi.org/10.21203/rs.3.rs-20412/v1

Mansdorf, I. J. (2020). Enforcing compliance with COVID-19 pandemic restrictions: Psychological aspects of a national security threat. Israeli Security, Regional Diplomacy, and International Law. Retrieved from https://www. preventionweb. net/news/view/70917

Ovenseri-Ogbomo, G., Ishaya, T., Osuagwu, U. L., Abu, E. K., Nwaeze, O., Oloruntoba, R., . . Langsi, R. (2020). Factors associated with the myth about 5G network during COVID-19 pandemic in sub-Saharan Africa. Journal of Global Health Reports, 4, e2020094. https://doi.org/10.29392/001c.17606

Pakistan, G. (2020). Coronavirus Attitude Tracker Pakistan - Wave 7 Results. Retrieved from Washington DC, USA: www.gallup-international.com

Plohl, N., \& Musil, B. (2020). Modeling compliance with COVID-19 prevention guidelines: The critical role of trust in science. Psychology, Health \& Medicine, 1-12. https://doi.org/10.1080/13548506.2020.1772988

Roser, M., Ritchie, H., Ortiz-Ospina, E., \& Hasell, J. (2020). Coronavirus pandemic (COVID-19). Our World in Data.

Schor, E., \& Fingerhut, H. (2020). Poll: US believers see message of change from God in virus. Retrieved from https://apnews.com/article/0bed79d024a56d2ac0b93bc51df80e9b

Seale, H., Heywood, A. E., Leask, J., Steel, M., Thomas, S., Durrheim, D. N., . . Kaur, R. (2020). COVID-19 is rapidly changing: Examining public perceptions and behaviors in response to this evolving pandemic. medRxiv. https://doi.org/10.1101/2020.05.04.20091298

Tang, D., Tou, J., Wang, J., Chen, Q., Wang, W., Huang, J., . . Zhao, D. (2020). Prevention and control strategies for emergency, limited-term, and elective operations in pediatric surgery during the epidemic period of COVID-19. World Journal of Pediatric Surgery, 3(1). https://doi.org/10.1136/wjps-2020-000122

Tierney, M., Stevens, K., \& Armbrust, V. (2020, April 7). Child welfare services and COVID-19: Four urgent Accenture. Retrieved from https://www.accenture.com/us-en/insights/public-service/coronavirus-child-welfare-our-key-actions

Van Natta, M., Chen, P., Herbek, S., Jain, R., Kastelic, N., Katz, E., . . Vattikonda, N. (2020). The rise and regulation of thermal facial recognition technology during the COVID-19 pandemic. Journal of Law and the Biosciences, 7(1). https://doi.org/10.1093/jlb/lsaa038

WHO. (2020a). Coronavirus. Geneva Retrieved from https://www.who.int/health-topics/coronavirus\#tab=tab_3

WHO. (2020b). Coronavirus disease 2019 (COVID-19): situation report, 72. Geneva

WMA. (2001). Declaration of Helsinki. Ethical principles for medical research involving human subjects.

Xiao, Y., \& Torok, M. E. (2020). Taking the right measures to control COVID-19. The Lancet Infectious Diseases, 20(5), 523-524. https://doi.org/10.1016/S1473-3099(20)30152-3

Zhao, Z., Li, X., Liu, F., Zhu, G., Ma, C., \& Wang, L. (2020). Prediction of the COVID-19 spread in African countries and implications for prevention and controls: A case study in South Africa, Egypt, Algeria, Nigeria, Senegal and Kenya. Science of the Total Environment, 138959. https://doi.org/10.1016/j.scitotenv.2020.138959 


\section{Appendix A. Supplementary table (S1)}

Table S1. Sample of online administered questionnaire for main outcomes

1. In recent days, have you worn a mask when leaving home?

\section{Always/ Sometimes/ Rarely/Not at all/Not sure}

2. In recent days, have you been washing your hands with soap under running water for at least 20 seconds each time?

\section{Always/ Sometimes/ Rarely/Not at all/Not sure}

3. Are you currently or have you been in (domestic/home) quarantine because of COVID-19?

\section{Yes/ No}

4. Are you currently or have you been in self-isolation because of COVID-19?

Yes/ No

5. Since the government gave the directives on preventing being infected, have you procured your mask and possibly sanitiser?

Yes/ No

6. Have you travelled outside your home in recent days using the public transport?

\section{Yes/ No}

7. Are you encouraging others that you encounter to observe the basic prevention strategies suggested by the authorities?

\section{Yes/ No}

8. How much have you changed the way you live your life because of the possibility of continuing of Coronavirus disease (COVID-19)?

A great deal/ A lot/ A moderate amount/A little/Not at all 


\section{Appendix B. Supplementary table (S2)}

Table S2. Adjusted odds ratio (aOR) and Confidence interval (CI) of demographic factors associated with compliance with the public health measures

\begin{tabular}{|c|c|c|c|c|c|c|c|c|}
\hline & Attended crowded place & Used Facemask & Self-quarantined & Self-isolated & Hand Sanitiser & Encouraged others & Hand washing & Out of state travel \\
\hline Final model variables & $\mathrm{aOR}[95 \% \mathrm{CI}]$ & $\mathrm{aOR}[95 \% \mathrm{CI}]$ & $\mathrm{OR}[95 \% \mathrm{CI}]$ & $\mathrm{aOR}[95 \% \mathrm{CI}]$ & $\mathrm{aOR}[95 \% \mathrm{CI}]$ & $\mathrm{OR}[95 \% \mathrm{CI}]$ & $\mathrm{aOR}[95 \% \mathrm{CI}]$ & $\mathrm{aOR}[95 \% \mathrm{CI}]$ \\
\hline \multicolumn{9}{|l|}{ SSA region } \\
\hline West Africa & Reference & Reference & Reference & Reference & & & & Reference \\
\hline East Africa & $1.59[0.99,2.54]$ & $2.65[1.83,3.85]$ & $1.01[0.71,1.43]$ & $1.04[0.72,1.50]$ & & & & $1.83[1.25,2.69]$ \\
\hline Central Africa & $3.13[2.16,4.54]$ & $6.62[4.25,10.31]$ & $0.60[0.43,0.83]$ & $0.76[0.54,1.06]$ & & & & $2.61[1.87,3.63]$ \\
\hline South Africa & $1.03[0.70,1.52]$ & $1.82[1.40,2.37]$ & $0.95[0.73,1.25]$ & $1.09[0.84,1.43]$ & & & & $0.94[0.68,1.30]$ \\
\hline \multicolumn{9}{|l|}{ Residence } \\
\hline Local & & Reference & Reference & & & & & \\
\hline Diaspora & & $1.37[0.90,2.08]$ & & & & & & \\
\hline \multicolumn{9}{|l|}{ Age grouping } \\
\hline $18-28$ years & Reference & & Reference & Reference & & Reference & Reference & Reference \\
\hline $29-38$ & $0.83[0.56,1.21]$ & & $0.67[0.49,0.90]$ & $0.65[0.49,0.87]$ & & $3.68[2.05,6.63]$ & $2.27[1.19,4.34]$ & $1.05[0.80,1.38]$ \\
\hline $39-48$ & $0.42[0.26,0.69]$ & & $0.56[0.38,0.80]$ & $0.48[0.33,0.69]$ & & $3.80[1.98,7.29]$ & $3.16[1.28,7.77]$ & $0.43[0.30,0.61]$ \\
\hline $49+$ years & $0.31[0.16,0.58]$ & & $0.47[0.31,0.72]$ & $0.43[0.28,0.65]$ & & $12.31[2.99,50.65]$ & $7.44[1.71,32.32]$ & $0.18[0.10,0.32]$ \\
\hline \multicolumn{9}{|l|}{ Sex } \\
\hline Male & & Reference & Reference & & & Reference & & \\
\hline Female & & $1.60[1.29,1.97]$ & $1.59[1.28,1.98]$ & & & $9.06[7.04,11.66]$ & & \\
\hline \multicolumn{9}{|l|}{ Employment } \\
\hline Employed & Reference & Reference & & & & & Reference & \\
\hline unemployed & $0.63[0.43,0.92]$ & $0.73[0.57,0.95]$ & & & & & $0.44[0.25,0.77]$ & \\
\hline \multicolumn{9}{|l|}{ Marriage status } \\
\hline Married & & Reference & Reference & Reference & Reference & & & \\
\hline Not married & & $0.76[0.60,0.97]$ & $1.51[1.13,2.01]$ & $2.02[1.52,2.70]$ & $0.48[0.27,0.85]$ & & & \\
\hline \multicolumn{9}{|l|}{ Religion } \\
\hline Christian & Reference & & & & & & & Reference \\
\hline Muslim & $0.45[0.25,0.80]$ & & & & & & & $0.61[0.40,0.94]$ \\
\hline \multicolumn{9}{|l|}{ Education } \\
\hline Postgraduate & & & & & Reference & & & \\
\hline Bachelor & & & & & $0.44[0.22,0.88]$ & & & \\
\hline Sec/primary & & & & & $0.56[0.23,1.38]$ & & & \\
\hline \multicolumn{9}{|l|}{ Live alone } \\
\hline No & Reference & & & & & & & \\
\hline Yes & $1.41[1.01,1.98]$ & & & & & & & \\
\hline
\end{tabular}


Number living together

$<3$ people

4-6 people

$6+$

Occupation

Not health related

Health care related

\section{Copyrights}

Copyright for this article is retained by the author(s), with first publication rights granted to the journal.

This is an open-access article distributed under the terms and conditions of the Creative Commons Attribution license (http://creativecommons.org/licenses/by/4.0/).

\section{Reference}

$1.16[0.72,1.86]$

$1.89[0.96,3.70]$

\section{Reference}

$1.41[1.03,1.92]$

. 